\title{
O Centro de Espaçonaves Tripuladas de Houston \\ - A Prática da Administração Matricial (*)
}

WILLIAM LITZINGER

Professor de Administração da Un. de San Francisco (EE.UU.)

\section{ALBERT MAVRINAC}

Professor de Governo na Fac. de Colby (EE.UU.)

JOHN WAGLE

Professor de Comercialização na Un. de

Oklahoma (EE.UU.)

Tradução de Marcos Henrique C. Cortes

Fonte: Révue Internationale des Sciences

Administratives, Vol. XXXVII, N. 1, 1970,

Bruxelas, Bélgica

\section{INTRODUÇÃO}

O histórico pouso na Lua representa na realidade um triunfo da inventividade do Homem. Dizer-se que a concretização do objetivo primordial do programa Apolo foi uma realização de equipe é referir-se ao óbvio. O êxito do programa foi o resultado de uma combinação de muitos elementos físicos e humanos. O principal dentre esses elementos foi a capacidade administrativa que agiu como catalizador para transformar os fatores desse feito da con-

- Os autores, durante os meses de junho a agosto de 1969, estiveram na condição de Professores Visitantes na Diretoria Administrativa do Centro de Espaçonaves Tripuladas de Houston.

R. Serv. públ., Brasilia, 109 (2) abr./jun. 1974 
secução potencial na dinâmica. Durante o programa Apolo, tal talento se manifestou por muitas formas desde a identificação dos problemas à sua solução. Este artigo serve para focalizar a atenção nas práticas e orientações administrativas desenvolvidas de maneira ímpar no Centro de Espaçonaves Tripuladas (CET) de Houston. Ele serve também como uma visão de conjunto da dinâmica de uma organização complexa e da articulação não-ortodoxa de energias e sistemas organizacionais.

\section{O CENTRO DE ESPAÇONAVES TRIPULADAS DE HOUSTON}

O Centro de Houston é uma das onze instalações da Administração Nacional de Aeronáutica e Espaço (NASA pela sigla em inglês). A missão global do CET consiste em administrar o desenvolvimento e a experimentação de espaçonaves e equipamento correlato, selecionar e treinar tripulações de vôo, e desenvolver e aplicar técnicas e controles de vôo espacial (Houston se torna o ponto focal de todos os vôos quando o Controle da Missão assume a direção doze segundos após o lançamento). A interdependência dos três elementos - espaçonave, tripulação e missão - requer que eles sejam administrados através de uma orientação de sistemas sinergísticos.

A estrutura formal da organização do CET, que é reproduzida no organograma padronizado da Figura 1, não reflete a realidade da administração do CET.

Uma aproximação maior da realidade da dinâmica administrativa do Centro é indicada na Figura 2. Ela é mais do que uma representação da "era espacial" de um sistema estruturalfuncional. Exatamente como os componentes de nosso próprio sistema solar são mantidos em justaposição pelas forças da Natureza, assim também cada "planeta" no CET deve sua posição a mais do que apenas interação com o "sol" (Diretor) ou sua(s) lua(s). Cada planeta (Diretoria) interage com todos os componentes do sistema para produzir um equilibrio ou estabilidade que serve para sus. tentar o sistema

\section{FILOSOFIA ADMINISTRATIVA}

Várias decisões iniciais que constituem a filosofia básica da NASA tiveram um impacto fundamental na or. ganização e administração do Centro de Espaçonaves Tripuladas. Uma decisão importante foi a de que a NASA seria um órgão que se incumbiria da administração técnica de uma equipe governo-empreiteiro-universidade em lugar de projetar e fabricar seu pró. prio material em instalações da NASA. (Durante a missão da Apolo 11 havia aproximadamente 4.400 funcionários públicos e 10.000 pessoas a serviço de empreiteiros diretamente engajados na missão no CET-Houston ou em torno dele). A natureza de pesquisa e desenvolvimento própria do progra. ma espacial exigiu um esforço de equipe entre o pessoal da NASA $e$ dos empreiteiros, trabalhando em coin junto para planejar o programa, determinar as necessidades, desenvolver 


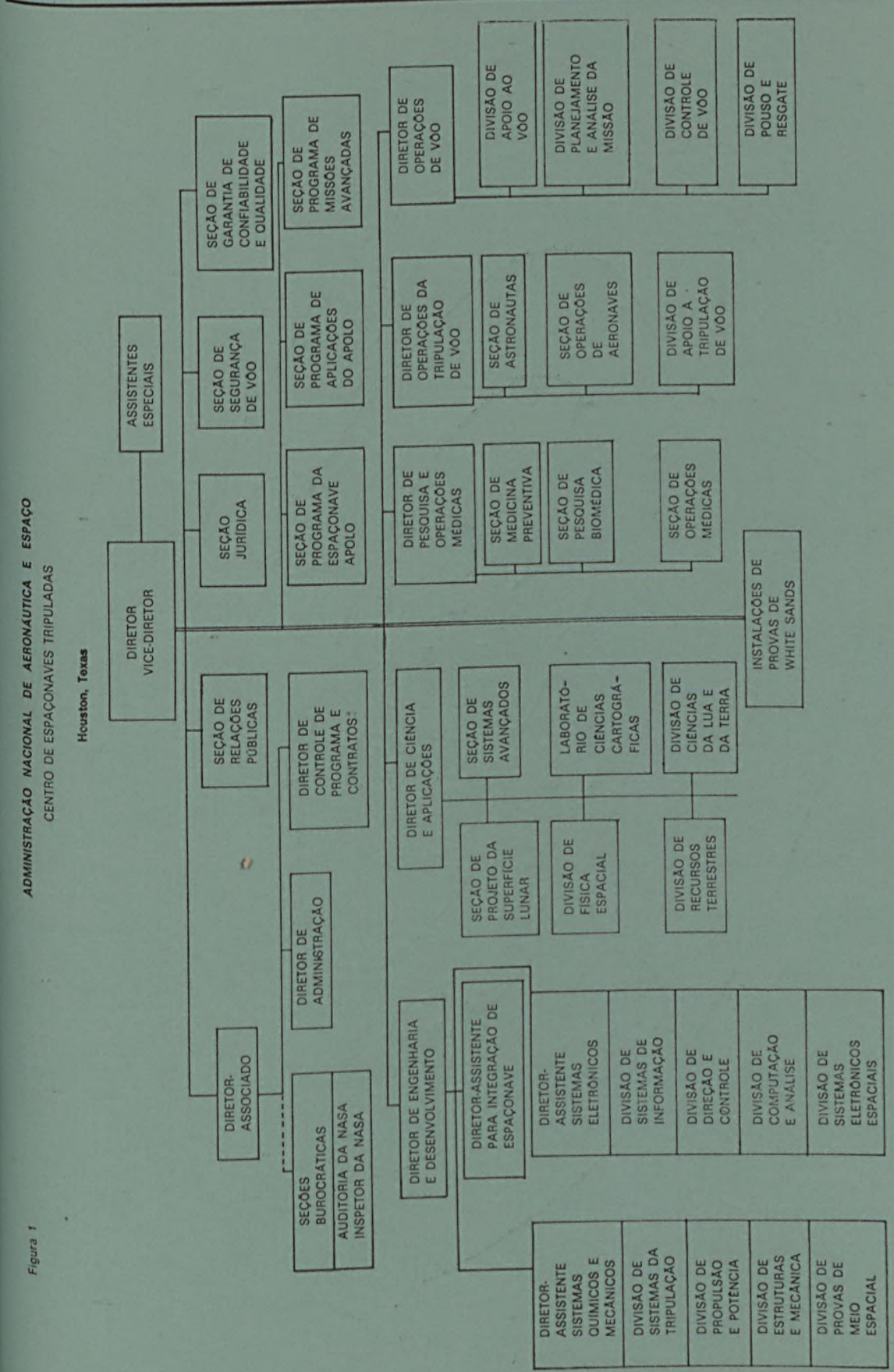

R. Serv. públ., Brasília, 109 (2) abr./jun. 1974 


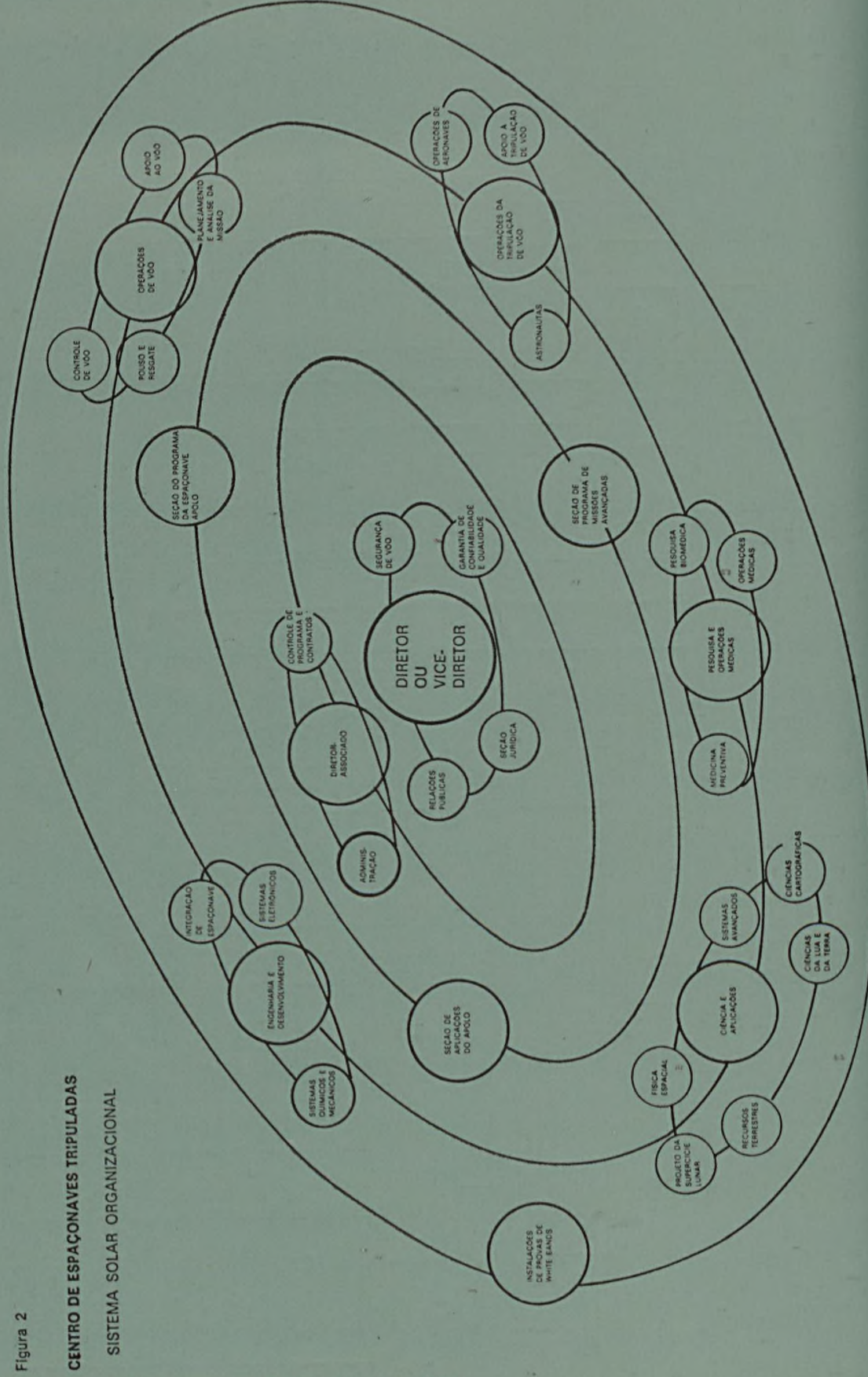

R. Serv. públ., Brasília, 109 (2) abr./jun. 1974 
as especificações e desenhar o material. Ela implicou também uma ênfase em encomendas que levou a importantes experiências no CET sobre a organização de atividades de encomenda.

As encomendas e todas as outras atividades do CET foram também afetadas de maneira significativa pela própria adoção pela NASA do sistema de administração matricial segundo o qual cada elemento de uma organiza ção se situa numa interseção de influências de outros elementos e ele mesmo influencia vários outros. É um sistema que tende a reduzir a visibilidade da autoridade e a realçar o consenso como um modo operativo. A NASA adotou também a orientação programática dentro da estrutura e do processo matricial.

O CET, devido a seu papel central na conquista da meta do primeiro pouco tripulado na Lua, é um teste do acerto da orientação da NASA. Como tal ele constitui um excelente estudo-modelo que náo só demonstra - que acontece na prática com tais Orientações administrativas como também lança luz sobre a natureza dos elementos-chaves dessas orientações.

\section{A SUPERFÍCIE DE CONTATO ENTRE A NASA E O CET}

O CET é, afinal, o que é basicamento devido à perícia administrativa de sua própria direção e à flexibilidade de seus próprios empregados. Contudo a filosofia administrativa global da NASA desempenha um papel-chave como moderador catalítico entre os diversos Centros Espaciais, incluindo
- CET porém incluindo também organizações importantes como o Centro Espacial Marshall, em Huntsville, Alabama e o Centro Espacial Kennedy, na Flórida. É a Central da NASA que, em última análise, atribui tarefas espaciais específicas aos vários centros e assegura a coordenação de um centro com o outro dentro de um programa determinado.

Além disso, o sistema matricial de administração no CET é paralelo ao sistema matricial da NASA. Esse próprio uso pela NASA do princípio matricial significa que as ordens finais da Central da NASA são formuladas somente depois de terem sido consultadas as diretorias e seções de programa no CET e em outros centros. Ele significa também que até certo ponto as diretorias do CET são inicialmente encorajadas a atuarem com considerável independência. A NASA serve assim para introduzir no processo de formulação de diretrizes considerações de longo prazo da estratégia do programa, incluindo aquelas baseadas nas realidades da politica e dos orçamentos nacionais. Seu programa e documentos da missão servem também como meios para ca. nalizar as funções de unidades determinadas do CET e fornece as linhas mestras para o controle pela cúpula dirigente do CET das operações do Centro.

O método pelo qual a NASA define funções e responsabilidades tanto dentro do CET como entre o CET e os outros centros, bem como a orientação subsidiária análoga pelo CET de suas próprias unidades, pressupõe que - CET é algo mais do que uma agre- 
gação de organizações voluntariosas lideradas e operadas por pessoas ativas e competentes. Ele pressupõe que a fluidez da concorrência é posta em ordem por uma direção que auxilia os homens a trabalhar como uma equipe.

\section{AS FORMAS ORGANIZACIONAIS DO CET}

O Centro de Espaçonaves Tripuladas está organizado tanto em termos de administração funcional como de administração programática. A organização funcional tem uma estrutura típica. Ela consiste de Diretorias responsáveis por: (1) Engenharia e Desenvolvimento; (2) Operações de Vôo; (3) Operações da Tripulação de Vôo; (4) Operações e Pesquisas Médicas; (5) Ciência Espacial e suas Aplicações; (6) Controle do Programa e Contratos; e (7) Administração. Cada uma delas funciona de maneira bastante autônoma e participa na medida necessária para atingir os objetivos globais do Centro.

A administração funcional proporciona uma direção profissional centralizada e monitoramento, avaliação e informação permanentes aos funcionários superiores do Centro a respeito de diretrizes e procedimentos em todo o âmbito do Centro e de práticas operacionais em uma dada área funcional. Em geral uma área funcional é uma disciplina profissional ou administrativa específica tal como Medicina, Ciência Espacial, Operações de Tripulação de Vôo, ou Controle de Programa e Contratos. Além disso essas unidades muitas vezes têm vínculos importantes com a comunidade profissional em geral, da qual podem obter recursos para agir sobre proble. mas específicos.

Por outro lado, a administração pro. gramática é a que foi estabelecida e feita sob medida para um programa específico como o Apolo. Ela atua como uma atividade de administração geral dirigida a integrar as atividades de planejamento, controle, supervisão, engenharia e fabricação vinculadas com a produção do artigo final. Qualquer organização programática é um sistema temporário. A consecução de sua meta significa o término daquela organização determinada. O Adminis trador do Programa não possui qualquer linha formal de autoridade sobre as unidades funcionais ào CET porém tem autoridade de determinação sobre a configuração dos elementos da mis. são.

Na operação administrativa do CET todo componente da organização é parte de um universo complexo. Os Diretores Funcionais e os Administra. dores de Programa são parceiros em uma aliança dirigida para o êxito da missão. Eles são impulsionados por pressões empíricas, bem como por dispositivos administrativos específicos, para cooperar em todas as fases do desenvolvimento e da execução do programa.

\section{PRINCÍPIOS DE ORGANIZAÇÃO MATRICIAL DO CET}

O conceito central que governa a tomada de decisões no CET é a administração matricial. Ela vê toda unidade da organização como um ponto de interseção de forças em competi- 
ção, com cada parte dando expressão particular à meta global da organização. As decisões operativas são produtos da interação de unidades especializadas lutando por uma parcela dos recursos totais do Centro.

Entretanto, uma parte chave da administração matricial tal como exemplificada no CET é a presença de elementos com o poder de decisão precisa, capaz de congelar o diálogo da tomada de decisões em pontos ad hoc. Em lugar da hierarquia e da pressão para se conformar às diretivas de cima, o estilo de administração matricial do CET tenta substituir o impulso da unidade operadora pela expressão dentro de um clima de respeito mútuo unido em torno de pontos fundamentais.

Por conseguinte, o CET projeta a um só tempo um forte tom de competição entre seções de programa e diretorias e um sentido de unidade e objetivo comum. De um lado, mais do que é comumente verdadeiro em instituições governadas por conceitos tradicionais de administração hierarquizada, no CET o jogo é sempre aberto, o bolo está sempre sendo partilhado e as exigências de tempo e reputação são inexoráveis. Por outro lado, os elementos estruturados que unificam são suplementados pela força da liderança.

\section{TENSÃO CRIADORA}

Cada uma das diretorias do CET é uma área de tensão entre as forças de integração e de fragmentação que atravessam a organização total do CET. As técnicas da administração do Centro são concebidas para realçar ambas essas tendências.

Tendências de desintegração derivam, por exemplo, da responsabilidade da Diretoria Médica de olhar pela saúde dos astronautas e de realizar experiências médicas nas missões. Analogamente, a Diretoria de Operações da Tripulação de Vôo precisa olhar pelo moral de meia centena de astronautas, todos homens altamente motivados cuja recompensa é o vôo espacial. E a Diretoria de Operações de Vôo é responsável por supervisionar uma missão em que a segurança da tripulação é primordial, em que as exigências de engenharia são pesadas, em que há um tempo limitado até para lidar com aspectos essenciais para a vida e a manutenção de uma trajetória exata. A Diretoria de Engenharia e Desenvolvimento é movida pela noção de ser a vanguarda dos pioneiros do vôo espacial, enfrentando os problemas de desenho de espaçonaves de uma forma imaginativa, antecipando novas modalidades de viagem espacial e de outras formas extra-terrestres acima e na superfície de luas e planetas, e aparando as enormes solicitações de outras diretorias em relação ao espaço. E a Diretoria de Ciência e Aplicações facilmente responde às pressões da comunidade científica no sentido de que seus interesses sejam representados no manuseio de experiências nas missões.

\section{TÉCNICAS UNIFICADORAS}

A administração superior introduziu uma quantidade de técnicas unificadoras no mundo de autarquias do Centro de Espaçonaves Tripuladas. Um dos 
conjuntos-chaves de dispositivos de controle na administração do CET está confiado ao Diretor-Associado. A ele são atribuídas a responsabilidade pelo planejamento e direção global das atividades administrativas e de direção necessárias para dar apoio aos programas em andamento do CET. Ele é o principal assessor do Diretor e do Vice-Diretor do Centro no que se refere a administração global de programas e operações. Foram identificadas duas entidades organizacionais abrangidas por sua esfera de autoridade : (1) Controle de Programa e Contratos e (2) Serviços Administrativos e de Apoio Técnico. Essas unidades têm a responsabilidade de fornecer administração de contratos, funções de encomendas e outros tipos de apoio administrativo e técnico para o Centro.

O Diretor-Associado não toma decisões estratégicas nem estabelece configurações operacionais. Ao contrário, ele traduz diretrizes em dinheiro, material e pessoal. Ele o faz através do controle que tem sobre o orçamento total do Centro de Espaçonaves Tripuladas, funções globais de encomenda em um estabelecimento acentuadamente voltado para a administração de contratos e administração global de pessoal.

Uma outra técnica unificadora importante foi a atribuição às Seções de Programa de um papel superior na tomada de decisões. A missão Apolo é suposta, em última análise, ser mantida coesa pela Seção do Programa da Espaçonave Apolo (SPEA), cujo principal funcionário é o Administrador do Programa.
Um dos instrumentos básicos de coordenação usados pela SPEA é a Junta de Controle da Configuração da Espaçonave Apolo (JCC). Esta Junta está incumbida dos projetos de cada missão determinada em todos os as. pectos - desde a forma e construçáo do módulo de comando e serviço até o desenho do equipamento de sustentação da vida fora do veículo e até a fixação dos parâmetros de tempo de cada missão. Os principais membros da JCC são os chefes das diretorias técnica do CET, eram alguns outros elementos-chaves também a integrem. O plano de uma missão é determinado pela JCC dentro dos limites impostos ao CET pela Central da NASA no Plano de Desenvolvimento do Pro. grama Apolo (PDP) $\theta$ é expresso em um conjunto de documentos de plane. jamento da missão que vão desde 0 Plano de Operações da Missão Apolo até o próprio Plano de Vôo. Todos os aspectos da missão, de experiências científicas a procedimentos de cancelamento, são expressos nesses do. cumentos de controle. O desenho de equipamento é aprovado em detalhes pela JCC. As decisões sobre desenhos e procedimentos básicos se seguem à apresentação à JCC em suas reuniões semanais por pessoal do CET ou representantes de organizações empreiteiras. Uma vez tomadas as decisões sobre desenho básico elas só podem ser modificadas por açăo da JCC.

Qualquer pessoa que tenha assistido a uma reunião da Junta de Controle de Configuração não pode deixar de ficar impressionada pelo valor de uma reunião que faz o pensamento maduro e imaginativo de funcionários 
superiores atuar sobre os aspectos operacionais essenciais de uma missão complexa. Contudo um princípio chave é o de que conquanto a JCC seja concebida como um meio pelo qual as opiniões de todas as seções e diretorias do CET possam ser, assim como as propostas específicas de empreiteiros, inseridas nas operações, a decisão final cabe ao Presidente da JCC (o Administrador da Seção do Programa da Espaçonave Apolo). Grupos de Controle de Configuração (GCC) específicos são constituídos para cuidar em maior detalhe de questões de configuração de equipamento. As modificações de equipamento ocorrem dentro de um conjunto de procedimentos de controle que permitem uma latitude considerável aos empreiteiros e aos GCCs na efetivação de modificações. Isso se aplica enquanto certos limites financeiros do custo das modificações não são ułtrapassados e enquanto são respeitadas as especificações de peso e cronograma. Quaisquer destas modificações (custo, peso, cronograma) têm de ser aprovadas pelos Grupos de Controle de Configuração ou pela Junta de Controle de Configuração do CET. Sempre que as modificações de equipamento possam vir a causar impacto sobre o trabalho de outros Centros da NASA faz-se necessária a aprovação das modificações propostas pela Central.

Embora as funções básicas de planejamento da missão sejam responsabilidade das Diretorias de Operações de Vôo e de Operações da Tripulação de Vôo, os complexos inter-relacionamentos de todos os aspectos da missão indicam que o controle em nível superior do processo total deve ficar com o Administrador do Programa da Espaçonave Apolo. $\mathrm{Na}$ realidade, porém, o sistema matricial modifica essa regra de concepção abstrata em um procedimento mais complexo. O Administrador controla todas as modificações que influiriam sobre os requisitos da missão, equipamento pesado ou leve, regras da missão, trajetórias, cronogramas, requisitos de propelentes e características de massas. Periodicamente são expedidos documentos de controle refletindo a configuração em vigor do equipamento da missão e o estado do planejamento. Outras juntas de configuração devem adaptar suas decisões a fim de refletir consonância com os documentos aprovadas pela JCC da Espaçonave Apolo. Divergências de opiniões são dirimidas durante as reuniões normais da JCC. Isso significa que, fora de uma faixa limitada de aspectos mínimos claramente discerníveis e dos quais o Administrador da SPEA pode dar conta, há todo um campo de problemas relacionados com a operação da missão no qual só pode haver acordo através de concordância entre pares.

A utilidade da JCC como um dispositivo de integração, coordenação, determinação e direção levou à constituição de comissões do tipo JCC em outros pontos do Centro de Espaçonaves Tripuladas, num esforço para colocar juntos elementos relevantes do Centro.

\section{A ADMINISTRAC̣ÃO DE SUBSISTEMAS}

A Junta de Controle de Configuração é ela própria uma expressão e extensão específicas da técnica matricial fundamental de administração 
de subsistema. A principal característica desse dispositivo reside na responsabilidade operacional simultânea de certas subunidades de diretorias funcionais perante a chefia da sua Diretoria e perante a Seção de Programa. Por exemplo, a Seção de Projeto da Superfície Lunar, da Diretoria de Engenharia e Desenvolvimento, responde ao chefe desta Diretoria e ao Administrador da Seção de Programa da Espaçonave Apolo.

Uma variante da técnica de subsistema é a colocação de várias unidades lotadas com engenheiros na Diretoria de Ciência a fim de facilitar as comunicações entre a comunidade científica e os elementos de engenharia do CET.

\section{LOCALIZAC̣ÃO CONJUNTA}

Uma aplicação do princípio do subsistema é a técnica de localização conjunta. Há vários exemplos em que pessoal de diferentes diretorias engajadas em um determinado projeto do programa é instalado junto. Em vários casos, pessoal de empreiteiros é colocado nos mesmos escritórios dos funcionários públicos. Isso ocorre, por exemplo, no edifício em que está o Controle da Missão no CET, onde pessoal da "Philco Corporation" está instalado permanentemente ao lado de funcionários públicos especialistas em operações de planejamento de contro. le da missão.

Uma versão um tanto invulgar de localização conjunta foi exemplificada pela realização pelo Administrador do Programa da Espaçonave Apolo de reuniões da JCC nos locais de trabaIho dos principais empreiteiros do Apolo. Assim, por exemplo, foram feitas reuniões com a "North American" em Downey, Califórnia, a respeito do módulo de comando e serviço. Analogamente foram feitas reuniões sobre o módulo lunar na fábrica da "Grumman" em Bethpage, Long Island.

\section{O "PACOTE DE tRABALHO"}

Para assegurar ainda mais o fluxo de comunicações entre especialistas do programa e em engenharia, o CET desenvolveu o sistema do "pacote de trabalho". Embora as diretorias funcionais tenham alguns fündos orçamentários atribuídos diretamente, o grosso de seus recursos financeiros operacionais provem de acordos com as seções de programa para o fornecimento de apoio técnico específico. É responsabilidade das seções de programa ou, na verdade, de qualquer diretoria funcional convencer uma diretoria a trabalhar consigo no desenvolvimento de equipamento e chegar a um acordo muito parecido com o que seria estabelecido com uma firma empreiteira particular. Dessa maneira os recursos de uma diretoria como a de Engenharia e Desenvolvimento foram aplicados a problemas como 0 do mecanismo e técnica de atracação do módulo de comando e serviço com o módulo de excursão lunar.

Uma outra importância do sistema de "pacote de trabalho" no processo administrativo do CET está em que ele permite o monitoramento sistemático pelo Diretor do Centro do traba- 
lho das diretorias em projetos do programa em termos de taxa de dispêndio de fundos, respeito do cronograma e qualidade de desempenho.

\section{EMPRESÁRIOS MATRICIAIS}

A administração matricial no CET é portanto um mundo de empresários individuais, cada um dos quais trabalha para atrair e reter talentos excepcionais. Cada um luta para garantir que seu grupo de homens é capaz de injetar suas próprias idéias específicas no desenvolvimento e execução de missões e programas dentro do quadro de diretivas amplas traçadas pela Central da NASA. Tudo isso está sujeito à coordenação e direção da chefia superior no CET e nas Seções de Programa.

Os críticos podem dizer que o sistema matricial do CET, fugindo às disposições hierárquicas tradicionais, pode funcionar e de fato funcionou devido às vastas somas que o povo nor. te-americano estava disposto a dar ao programa Apolo. É igualmente provável que esse sistema funcionou devido a que seu método de participação democrática e tomada de decisão por meio de negociação, qualificada pela previsão de uma firme tomada de decisão em determinados momentos e lugares, tudo mantido coeso por uma chefia experiente, é especialmente compativel com as modernas filosofias de administração. Preso a um ob. jetivo nítido e a um sistema claro de administração de contratos, ele demonstrou ser um estimulante de inovações em um sistema de ordem fluida.

\section{A FUNÇÃO DE ENCOMENDA - UMA APLICAÇÃO DO CONCEITO ADMINISTRATIVO DO CET}

Desde seu início em 1961, a administração no CET foi orientada para progredir através de mudanças. Essa concepção é ilustrada pelo fato de que durante os oito anos de existência do Centro foram feitas dezessete reorganizações. Através dessas mudanças, a administração nunca hesitou em afastar-se da estrutura organizacional tradicional a fim de melhorar o desempenho funcional.

A função de encomenda serve como um exemplo de um desvio para uma disposição não-ortodoxa de organização industrial, embora não seja desconhecida em certas operações governamentais. A atual estruturação para encomendas foi concebida em 1967 pela administração do CET como meio de dividir a carga de trabalho e resolver problemas específicos. Antes dessa época, todas as atividades de encomendas estavam concentradas em uma divisão da Diretoria de Administração. A divisão subseqüente de trabalho resultou em que os principais programas de pesquisa e desenvolvimento foram atribuídos à recém-criada Diretoria de Controle de Programa e Contratos. Os programas de apoio continuaram na Divisão de Encomendas dentro da Diretoria de Administração.

Pode-se dizer que a administração descartou a idéia de que o organograma tinha de ser um exemplo de livro didático e, em vez disso, simplesmente encarou a nova estrutura à luz de como se poderia melhor levar a cabo 
a tarefa especial e invulgar com o pessoal disponível.

Havia duas razões para se adotar essa estrutura organizacional dividida. Em primeiro lugar, para possibilitar a alguns elementos do pessoal superior responsável por encomendas do CET concentrar-se em trabalho somente com os programas principais e livrálos do trabalho relacionado com encomendas mais baratas ou menos complicadas. Havia sido descoberto que os contratos pequenos, de menor importância, continham problemas que, sob o sistema antigo, obrigavam a administração superior de encomendas a dispender tanto tempo e esforço que os contratos importantes estavam recebendo atenção insuficiente. Essa estruturação foi, por conseguinte, um esforço para separar esses contratos menos importantes e tornar possível para o pessoal superior encarregado de encomendas concentrarse nos programas mais custosos e complicados.

Em segundo lugar, a mudança foi feita a fim de alinhar mais intimamente as outras atividades da administração de recursos, incluindo orçamentação, análise de custos e elaboração de cronograma, com os principais contratos de pesquisa e desenvolvimento. Integrando-se essas funções em uma única organização, fez-se uma tentativa de estabelecer o controle no âmbito de todo o Centro da administração de todos os programas. A seção de Controle de Programa e Contratos apoia diretamente os principais programas de pesquisa e desenvolvimento do Centro na execução dessas especializações funcionais, e também servirá como ponto focal para a análise integrada do estado do programa. Tal análise proporciona um meio melhor de correlacionar o estado dos principais programas da espaçonave com 0 esforço operacional requerido para apoiá-los e fornece um meio melhor para analisar as inter-relações dos mesmos.

A Diretoria de Controle de Programa e Contratos está encarregada da negociação e administração de contratos relacionados com os programas principais de pesquisa e desenvolvimento atribuídos ao Centro. A linha de relacionamento leva ao Diretor-As. sociado do Centro. Isso significa que, no que se refere a encomendas, a diretoria é responsável pelo estabe. lecimento, execução e controle de diretrizes relativas às atividades das seções de programa.

Tem havido exceções a esta regra e existe a pergunta sem resposta $\mathrm{so}^{\circ}$. bre o que é e o que não é um programa principal de pesquisa e desenvolvimento. Para ilustrar a divisão de trabalho, o módulo de comando e serviço da Apolo é um programa principal de encomenda a cargo da Dire. toria de Controle de Programa e Contratos. As encomendas para esse programa incluem a cápsula espacial Apolo e seu equipamento de apoio. Por outro lado, a Divisão de Encomendas da Diretoria de Administraçăo cuida de contratos que atendem ao Centro de Espaçonaves Tripuladas em itens como equipamento, suprimentos. pesquisadores científicos destacados etc. Estes dois exemplos são bem definidos e oferecem pouca dificuldade para serem corretamente situados 
em cada um dos dois setores de encomendas. Entretanto, a Divisão de Encomendas da Administração também é responsável por programas principais de apoio no campo da pesquisa e desenvolvimento. Não há aparentemente linhas nítidas de distinção entre os programas de apoio e os que não o são, e entre os que deveriam ser atribuídos à Diretoria de Administração e os que deveriam ser confiados à Diretoria de Controle de Programa e Contratos.

\section{PRós E CONTRAS DA FUNÇÃo DIVIDIDA DE ENCOMENDAS}

As desvantagens são sentidas basicamente dentro dos dois grupos de encomendas e na maioria dos casos se referem a problemas de pessoal. Existe a possibilidade de que o pessoal encarregado de encomendas no grupo que cuida dos contratos menores, menos importantes, se sinta descontente por sentirem que a administração superior considera seu trabalho menos importante. E um fato que a divisão de especialistas em encomendas entre as diretorias diminuiu a flexibilidade no trato do pessoal. Há muito pouco deslocamento de especialistas de uma diretoria para outra. No treinamento se verifica às vezes uma duplicação de esforços e, em alguns casos, o perigo de ministrar treinamento partindo de pontos de vista diferentes.

Tanto a Central da NASA como os empreiteiros se encontram lidando com duas seções diferentes de encomendas no CET. As comunicações entre os dois grupos de encomendas são mais difíceis e emperradas do que sob o antigo esforço único de encomendas. É possível criar-se uma situação em que o comprador de um dispositivo subsidiário não possui informação suficiente sobre 0 equipamento principal, o que torna mais difícil para ele maximizar seu esforço de compra.

O objetivo originário do estabelecimento da nova Diretoria de Controle de Programa e Contratos abrangia a meta de proporcionar às encomendas e à orçamentação um apoio que não seria completamente dominado pelo ponto de vista de uma seção de programa. Este era um objetivo difícil de atingir devido ao fato de que o pessoal que trabalhava em atividades relacionadas com encomendas na Seção de Programa não tinha qualquer responsabilidade direta para com o Diretor do Controle de Programa e Contratos. No caso do programa Apolo tentou-se uma solução parcial com a designação desse Diretor como Administrador de Contratos e Recursos na Seção de Programa da Espaçonave Apolo, tornando assim esse grupo de pessoal diretamente responsável perante ele até onde estivessem envol. vidas essas funções relacionadas com encomendas.

Embora haja desvantagens em se ter dois grupos de encomendas, a divisão de trabalho parece realmente ter seu mérito. Ela possibilita a concentração com pessoal de alto nível em programas principais e coloca junto funções importantes. Conquanto possam ser prejudicadas as comunicações entre o grupo de encomendas de contratos principais e o grupo subsidiário, há a compensação de melhoria nas comu- 
nicações entre orçamento e análise de custos dentro de encomendas principais de pesquisa e desenvolvimento. $\mathrm{Se}$ os resultados parecerem superar as desvantagens, é bem provável que essa disposição peculiar seja mantida mesmo que o Centro de Espaçonaves Tripuladas possa sofrer outras mudanças de estrutura. A esta altura é ainda cedo demais para se avaliar plenamente os efeitos dessa modificação. Ela continua sendo uma questão controvertida.

\section{EPÍLOGO}

A Apolo 11 tem sido mencionada como o conjunto de equipamento mais complicado jamais concebido pelo Homem. A mente se atordoa quando se tenta visualizar a configuração total desse empreendimento desde os $\mathrm{mi}$ Ihões de peças de equipamento até 0 próprio vôo da missão, que abrange uma rede de comunicações de âmbito mundial. As dimensões administrativas da tarefa são impressionantes $\theta$ não obstante, sob isso tudo, encontrase um fator comum.

Este artigo tentou lançar luz sobre a magnitude dessa realização administrativa, observando algumas das ino. vações administrativas e chamando atenção para um segmento do esforço total. O segmento administrativo-gerencial é talvez o menos atraente e é passível de ser encoberto durante a euforia da realização, mas ele desempenha um papel vital para essa realização. 